\title{
Gonococcal resistance can be viewed productively as part of a syndemic of antimicrobial resistance: an ecological analysis of 30 European countries
}

\author{
Chris Kenyon ${ }^{1,2^{*}}$ D, Sheeba S. Manoharan-Basil ${ }^{1}$ and Christophe Van Dijck ${ }^{1}$
}

\begin{abstract}
Background: It is unclear how important bystander selection is in the genesis of antimicrobial resistance (AMR) in Neisseria gonorrhoeae.

Methods: We assessed bystander selection in a novel way. Mixed-effects linear regression was used to assess if country-level prevalence of gonococcal AMR in 30 European countries predicts homologous AMR in other bacteria. The data used was from the European Antimicrobial Resistance Surveillance Network.

Results: The prevalence of gonococcal ciprofloxacin resistance was found to be positively associated with AMR prevalence in $E$. coli (coef. 0.52; $P=0.007$ ), Acinetobacter spp. (coef. 0.13; $P=0.044$ ) and Pseudomonas aeruginosa (coef. 0.36; $P=0.020$ ) but not Klebsiella pneumoniae. Azithromycin resistance in $N$. gonorrhoeae was positively associated with macrolide resistance in Streptococcus pneumoniae (coef. $0.01 ; P=0.018$ ). No association was found for cephalosporins.

Conclusions: Gonococcal AMR is linked to that in other bacteria. This finding is likely explained by high antimicrobial consumption in affected populations and provides additional motivation for strengthening antimicrobial stewardship programs.
\end{abstract}

Keywords: Gonorrhoea, Neisseria gonorrhoeae, Fluoroquinolones, Macrolides, Antimicrobial resistance, Stewardship, Antibiotic consumption, Bystander selection

\section{Background}

Neisseria gonorrhoeae has developed antimicrobial resistance (AMR) to every major class of antimicrobials used to treat it $[1,2]$. There are real concerns that it may be untreatable with available antimicrobials in the not too distant future $[2,3]$. Understanding the determinants of AMR in $N$. gonorrhoeae is vital to prevent the future emergence of AMR. Initially, it was thought that the

\footnotetext{
* Correspondence: ckenyon@itg.be

${ }^{1}$ HIV/STI Unit, Institute of Tropical Medicine, 2000 Antwerp, Belgium 2Division of Infectious Diseases and HIV Medicine, University of Cape Town, Anzio Road, Observatory, Cape Town 7700, South Africa
}

major AMR determinant was exposure to antibiotics used to treat gonorrhoea [4-6]. The appreciation that $N$. gonorrhoeae is asymptomatic for much or most of the time it circulates in a population means that antibiotics used for other indications needed to be considered (bystander selection) [7]. Since gonococcal infections cluster with other STIs, a widely held formulation of this view was that bystander selection was predominantly confined to antibiotics used to treat other STIs (termed the STI bystander theory) [8]. While authors have speculated that drugs such as macrolides used to treat chlamydial and Mycoplasma genitalium genital infections may drive

(c) The Author(s). 2020 Open Access This article is licensed under a Creative Commons Attribution 4.0 International License, which permits use, sharing, adaptation, distribution and reproduction in any medium or format, as long as you give appropriate credit to the original author(s) and the source, provide a link to the Creative Commons licence, and indicate if changes were made. The images or other third party material in this article are included in the article's Creative Commons licence, unless indicated otherwise in a credit line to the material. If material is not included in the article's Creative Commons licence and your intended use is not permitted by statutory regulation or exceeds the permitted use, you will need to obtain permission directly from the copyright holder. To view a copy of this licence, visit http://creativecommons.org/licenses/by/4.0/. The Creative Commons Public Domain Dedication waiver (http://creativecommons.org/publicdomain/zero/1.0/) applies to the data made available in this article, unless otherwise stated in a credit line to the data. 
AMR in $N$. gonorrhoeae, little direct evidence to support this notion has been published [9]. One study has, however, found that the prevalence of macrolide AMR in Treponema pallidum, the bacterium responsible for syphilis, was strongly associated with population-level consumption of macrolides [10]. Other studies have suggested that antibiotic consumption for all indications plays a role (community bystander theory; Fig. 1) [7]. Understanding which of these theories is correct has important implications. If the former is true, then preventing the further emergence of gonococcal AMR could be accomplished by interventions such as antimicrobial stewardship limited to within STI services. If total antibiotic consumption played a role, then stewardship efforts to reduce antibiotic consumption in the whole community would be important [11].

Ecological studies have reached different conclusions regarding the association between general antimicrobial consumption and the emergence of AMR in N. gonorrhoeae, with some studies finding no association [12] and others finding an association [11, 13, 14]. Given the complexity of resistance ecology and the crudeness of the measurement tools at our disposal, these differences in findings are not too surprising [15]. For example, population-level antimicrobial exposure is typically measured as defined daily doses (DDD) per 1000 persons. The effect of exposure on AMR, however, depends on a variety of pharmacokinetic and other variables. Thus, a population that uses a higher and more effective dosing schema of antibiotics may have a higher DDD but a lower probability for inducing AMR to that antibiotic [15]. Exposure in a remote location may also result in AMR, which may then spread via travel to populations without the exposure [16]. This problem is particularly important for $N$. gonorrhoeae where travel has been shown to have played a vital role in the spread of AMR [16]. The problem is further compounded by horizontal gene transfer of AMR-conferring DNA from different bacterial species, where the AMR may persist (and travel) for years following exposure [17-20]. The
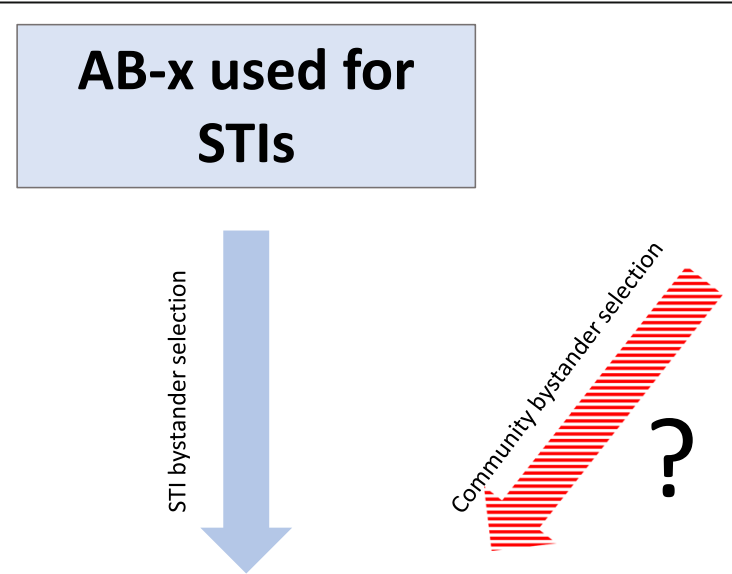

\section{AB-x used for all indications}

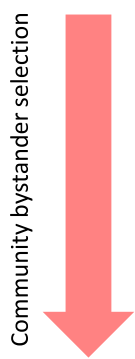

AMR to $x$ :

- N.gonorrhoeae

- M. genitalium

- T. pallidum

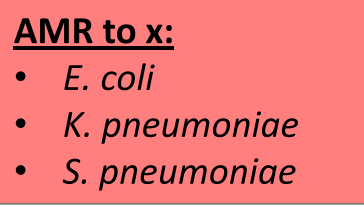

AMR to $x:$

E. coli

K. pneumoniae

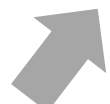

\section{Other determinants of}

AMR to $x$

Fig. 1 Conceptual framework for understanding how different forms of bystander selection could result in N. gonorrhoeae antimicrobial resistance (AMR) to the antibiotic-x (AB-x). The blue-pathway represents STI bystander selection where the use of antibiotic-x to treat STIs selects for AMR to other STIs that were not the target of the antibiotic. The red-pathway depicts community bystander selection whereby high-levels of consumption of antibiotic- $x$ would select for resistance to ' $x$ ' in circulating commensal and pathogenic bacteria. This community bystander selection could also act on STIs (striped red arrow), one of the hypotheses tested in this paper. The other hypothesis tested is that the prevalence of AMR to ' $x$ ' in N. gonorrhoeae will be positively associated with that in Escherichia coli and other pathobionts 
emergence of AMR may also be due to a short, concentrated period of exposure in a particular subpopulation and the AMR irreversible despite reduced antimicrobial exposure. These features mean that traditional countrylevel ecological analyses may miss associations between antimicrobial exposure and resistance.

These limitations motivated the current study where we approach the problem via a novel methodology. In addition to assessing the traditional association between antimicrobial consumption and gonococcal AMR, we analyze the association between gonococcal AMR and homologous AMR in other pathobionts. The hypothesis we test is that gonococcal AMR is associated with AMR in these pathobionts (Fig. 1). Finding evidence of such an association, we argue that this is most parsimoniously explained by all these bacteria being exposed to high levels of the respective antimicrobial for all indications.

\section{Methods \\ Data \\ Antimicrobial resistance data}

The AMR data was taken from the European Centre for Disease Prevention and Control (ECDC) Surveillance Atlas which reports resistance prevalence estimates from the European Antimicrobial Resistance Surveillance Network (EARS-Net) - the EU's main surveillance system for AMR in bacteria that cause serious infections. All 28 EU Member States and two EEA countries (Iceland and Norway) participate in EARS-Net. The countries provide data for all eight species under surveillance (Escherichia coli, Klebsiella pneumoniae, Streptococcus pneumoniae, Acinetobacter spp., Pseudomonas aeruginosa, Enterococcus faecalis, Enterococcus faecium, Staphylococcus aureus), with the exception of Greece which did not report data on $S$. pneumoniae. Only data from invasive (blood and cerebrospinal fluid) isolates are included in EARS-Net. This is done to limit biases that may emerge if isolates from all anatomical sites were included. Further details can be found in the EARS-Net reporting protocol [21]. The system depends on national network representatives in each participating country, reporting their locally tested susceptibility data to The European Surveillance System on an annual basis. This data is available for public access at https://www.ecdc.europa. eu/en/surveillance-atlas-infectious-diseases

The $N$. gonorrhoeae AMR surveillance data was extracted from the same ECDC Surveillance Atlas. This data comes from the Euro-Gonococcal Antimicrobial Surveillance Programme which uses a different methodology and includes a sentinel AMR surveillance program that tests a representative number of isolates from EU/ EEA member states every year for a range of antimicrobials, through a hybrid centralized/decentralized system [22, 23]. Data is available from 2000 (or later) to 2018.
The ECDC Surveillance Atlas reports gonococcal AMR for ciprofloxacin (a fluoroquinolone), azithromycin (a macrolide), cefixime and ceftriaxone (both Extended Spectrum (ES) cephalosporins) by country and year for 30 countries from 1997 to 2018. Since our hypothesis tested homologous class bystander selection, we limited our analysis to the 5 bacterial species that reported AMR for fluoroquinolones, macrolides or ESCephalosporins (E. coli, K. pneumoniae, S. pneumoniae, Acinetobacter spp., $P$. aeruginosa). The following minimum inhibitory concentration (MIC) breakpoints were used to define gonococcal antimicrobial resistance: Azithromycin: >0.5 mg/L, Cefixime: > $0.12 \mathrm{mg} / \mathrm{L}$, Ceftriaxone: > $0.12 \mathrm{mg} / \mathrm{L}$, Ciprofloxacin: $>0.06 \mathrm{mg} / \mathrm{L}[1,24]$. The breakpoints used for the other species are detailed elsewhere $[22,23]$. We use the term 'antimicrobial resistance' in its broadest sense to include reduced susceptibility.

\section{Antimicrobial consumption data}

Data from the European Surveillance of Antimicrobial Consumption (ESAC) were used as a measure of national general population-level antimicrobial drug consumption $[25,26]$. ESAC provides open access to the data collected on antimicrobial use in ambulatory care and hospital care in 30 European countries [25, 26]. ESAC reports antimicrobial consumption as the number of defined daily doses (DDD) per 1000 inhabitants following the World Health Organization guidelines [26, 27]. One DDD is defined as the average maintenance dose per day for a drug used in its main indication for adults [26]. In our study, we used three measures of country-specific antimicrobial drug use in ambulatory care: Cephalosporins/other Beta lactams (ATC group J01D), fluoroquinolones (ATC group J01MA), macrolides, lincosamides and streptogramins (ATC group J01F). Data was available from 1998 to 2018.

\section{Analyses \\ Associations between AMR in N. gonorrhoeae and other species}

For each antibiotic class, mixed effects linear regression was used to assess the association between the prevalence of AMR in N. gonorrhoeae and each of the other bacterial species. The following mixed effects linear model was used:

(N.gonorrhoeae_resistance-to-X in year $\mathrm{Y}$ and country C) $\sim$ (Species- $Z$ _resistance-to- $X$ in year $Y$ and country $C)+($ random intercept for country C) + intercept + error, where species-Z is one of $E$. coli, K. pneumoniae, S. pneumoniae, Acinetobacter spp. or P. aeruginosa, and $\mathrm{X}$ could be fluoroquinolones, macrolides or ESCephalosporins.

We represented the visual associations in AMR between $N$. gonorrhoeae and the other species with scatterplots using peak AMR prevalence, which was defined as the maximum AMR prevalence attained in each country for 
the period under observation. The 'maximum AMR prevalence' variable was only used in the generation of Fig. 2.

\section{Associations between AMR and antimicrobial consumption} In separate analyses for each relevant antimicrobialspecies combination, mixed effects linear regression was used to assess the correlation between prevalence of
AMR and antimicrobial consumption in the preceding year. The following mixed effects linear model was used:

(MIC/resistance in year $\mathrm{Y}$ and country $\mathrm{C}) \sim($ antimicrobial consumption in year $\mathrm{Y}-1$ and country C) $+($ random intercept for country C) + intercept + error.

The statistical analyses were performed in Stata 16.0. A $P$-value of $<0.05$ was regarded as significant. a

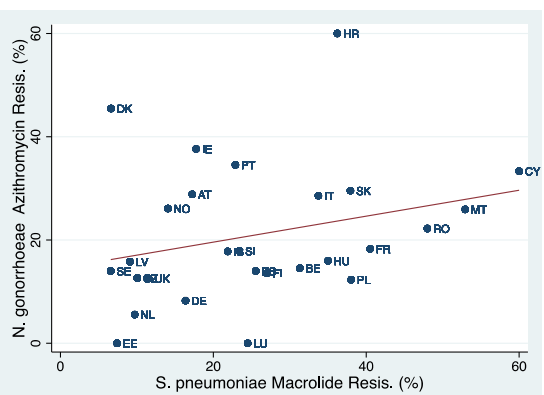

b
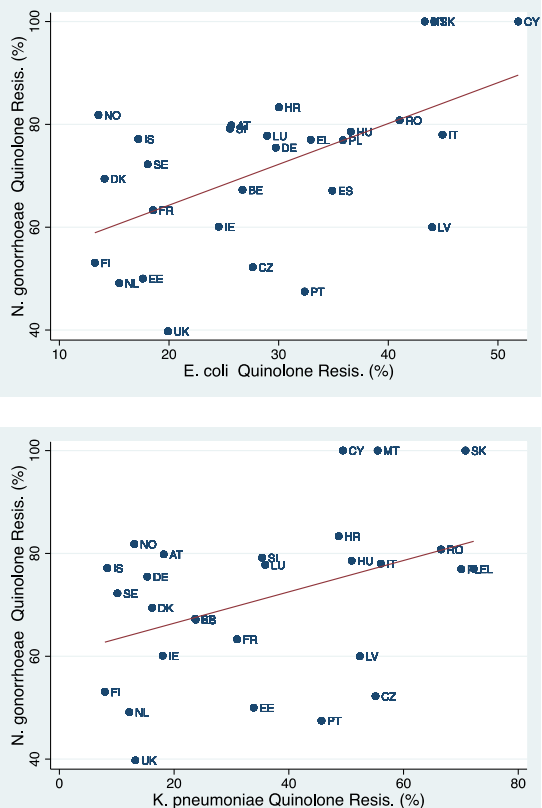

C

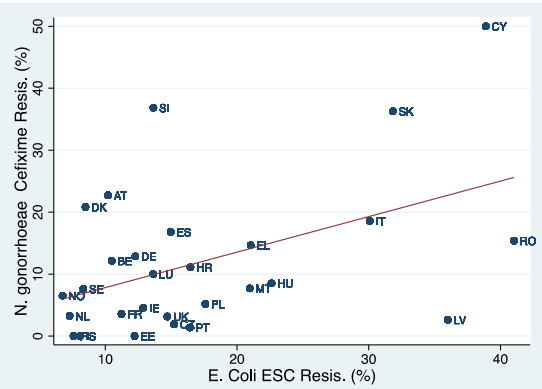

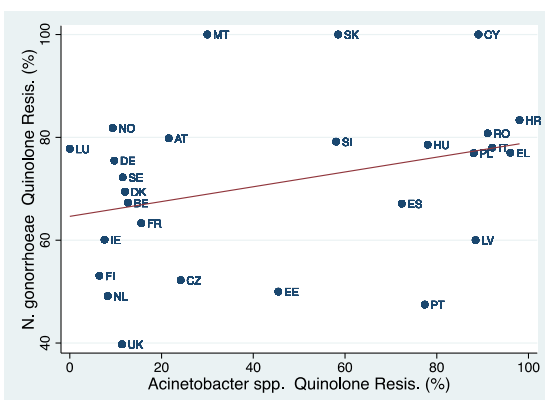
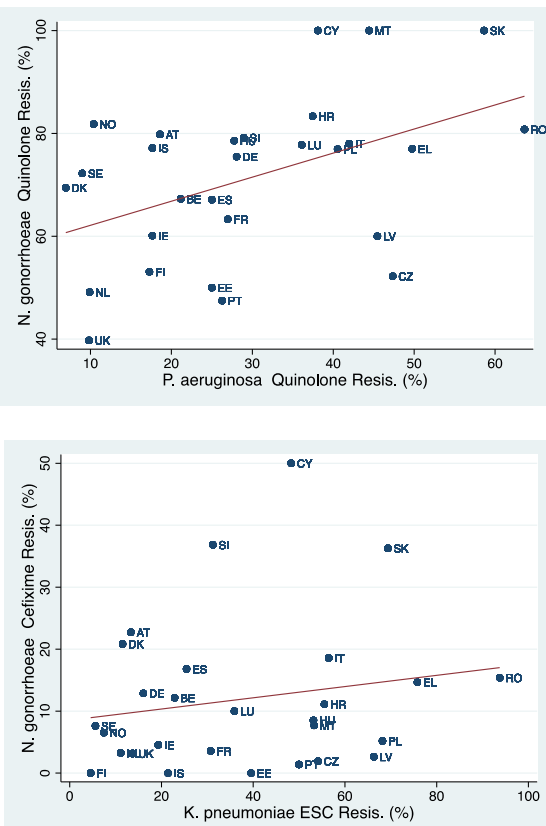

Fig. 2 Association between peak antimicrobial resistance prevalence (2000 to 2018) in Neisseria gonorrhoea and other bacteria for (a) Macrolides Streptococcus pneumoniae, (b) Fluoroquinolones. - Escherichia coli, Klebsiella pneumoniae, Pseudomonas aeruginosa, Acinetobacter spp. and (c) Extended Spectrum Cephalosporins (ESC) - Escherichia coli and Klebsiella pneumoniae 


\section{Ethics approval}

This analysis involved ecological analyses of public access data and thus no Ethics approval was necessary.

\section{Results}

There were large variations (up to 300 -fold) in the consumption of cephalosporins, fluoroquinolones and macrolides between countries (Table 1, Figures S1-S2). The median consumption of each class of antibiotic did not change by more than 20\% between 1997 and 2018 .

For each of the bacterial species, the prevalence of AMR varied considerably between countries (Table 1, Figures S1-S2). There were marked increases in ESCephalosporin and fluoroquinolone resistance over time in both $E$. coli and $K$. pneumoniae. The prevalence of fluoroquinolone resistance in $N$. gonorrhoeae declined over time.

\section{Association between $\mathrm{Ng} \mathrm{AMR}$ and other bacteria Fluoroquinolones}

The prevalence of gonococcal AMR was positively associated with AMR prevalence in E. coli (coef. 0.52; $P=$ 0.007), Acinetobacter spp. (coef. 0.13; $P=0.044$ ) and $P$. aeruginosa (coef. $0.36 ; P=0.020$ ) but not $K$. pneumoniae (Table 2; Fig. 2).

\section{Macrolides}

Azithromycin resistance in $N$. gonorrhoeae was positively associated with macrolide resistance in $S$. pneumoniae (coef. 0.01; $P=0.018$; Table 2; Fig. 2).

\section{ESCephalosporins}

No significant associations were found (Table 2; Fig. 2).
Association between AMR and antimicrobial consumption Fluoroquinolones

The consumption of fluoroquinolones was positively associated with AMR prevalence in E. coli (coef. 6.13; $P<$ 0.001), Acinetobacter spp. (coef. 4.8; $P<0.001), N$. gonorrhoeae (coef. 3.9; $P=0.047$ ) and $K$. pneumoniae (coef. 5.4; $P<0.001$ ) but not $P$. aeruginosa (Table 3 ).

\section{Macrolides}

Macrolide resistance in S. pneumoniae (coef. 2.39; $P<$ 0.001 ), but not $N$. gonorrhoeae was associated with macrolide consumption (Table 3).

\section{ESCephalosporins}

No significant associations were found (Table 3).

\section{Discussion}

We found that the prevalence of gono- and pneumococcal resistance to macrolides was positively associated. Likewise, gonococcal fluoroquinolone resistance was associated with homologous resistance in three of the 4 gram-negative bacteria assessed. No associations with ESCephalosporin resistance were found. In keeping with a previous analysis of European data, only fluoroquinolone consumption was found to be associated with homologous gonococcal resistance [13]. Fluoroquinolone AMR was significantly associated with consumption for all four of the other bacteria assessed. These findings suggest that fluoroquinolone consumption in the general population (community bystander selection), is a parsimonious explanation for variations in fluoroquinolone resistance in these bacteria, including $N$. gonorrhoeae. Of note, these associations were strongest with $E$. coli which is unsurprising if we recall that $E$. coli is the most prevalent of all the bacteria considered in the general human

Table 1 Variation in antimicrobial consumption and resistance to cephalosporins, fluoroquinolones and macrolides for six bacterial species in 30 European Countries. Values reported as medians (interquartile ranges)

\begin{tabular}{|c|c|c|c|c|c|c|c|c|c|c|c|c|c|c|c|c|}
\hline & \multicolumn{4}{|c|}{$\begin{array}{l}\text { Antimicrobial } \\
\text { consumption }\end{array}$} & \multicolumn{12}{|c|}{ Antimicrobial Resistance } \\
\hline & \multirow[b]{2}{*}{1997} & \multirow[b]{2}{*}{ FD } & \multirow[b]{2}{*}{2018} & \multirow[b]{2}{*}{ FD } & \multicolumn{2}{|c|}{$\begin{array}{l}\text { Neisseria } \\
\text { gonorrhoeae }\end{array}$} & \multicolumn{2}{|c|}{ Escherichia coli } & \multicolumn{2}{|c|}{$\begin{array}{l}\text { Klebsiella } \\
\text { pneumoniae }\end{array}$} & \multicolumn{2}{|c|}{$\begin{array}{l}\text { Streptococcus } \\
\text { pneumoniae }\end{array}$} & \multicolumn{2}{|c|}{$\begin{array}{l}\text { Acinetobacter } \\
\text { spp. }\end{array}$} & \multicolumn{2}{|c|}{$\begin{array}{l}\text { Pseudomonas } \\
\text { aeruginosa }\end{array}$} \\
\hline & & & & & 2009 & 2018 & 2000 & 2018 & 2005 & 2018 & 2005 & 2018 & 2005 & 2018 & 2005 & 2018 \\
\hline $\mathrm{N}$ & 14 & & 29 & & 17 & 27 & 4 & 29 & 21 & 29 & 26 & 28 & 26 & 28 & 26 & 29 \\
\hline ESCephalosporin & $\begin{array}{l}1.7 \\
(0.6- \\
4.0)\end{array}$ & 313 & $\begin{array}{l}1.9 \\
(0.6- \\
2.7)\end{array}$ & 262 & $\begin{array}{l}0.9 \\
(0.0- \\
6.4)^{a}\end{array}$ & $\begin{array}{l}0.0 \\
(0.0- \\
2.2)^{a}\end{array}$ & $\begin{array}{l}0.2 \\
(0.1- \\
1.9)\end{array}$ & $\begin{array}{l}13.8 \\
(9.6- \\
19.3)\end{array}$ & $\begin{array}{l}7.1 \\
(4.1- \\
27.7)\end{array}$ & $\begin{array}{l}30.8 \\
(12.8- \\
53.3)\end{array}$ & NA & NA & NA & NA & NA & NA \\
\hline Fluoroquinolone & $\begin{array}{l}1.0 \\
(0.5- \\
1.6)\end{array}$ & 13.8 & $\begin{array}{l}1.2 \\
(0.8- \\
2.3)\end{array}$ & 7.0 & $\begin{array}{l}70.0 \\
(49.1- \\
79.2)\end{array}$ & $\begin{array}{l}55.0 \\
(44.4- \\
60.0)\end{array}$ & $\begin{array}{l}3.8 \\
(2.5- \\
6.0)\end{array}$ & $\begin{array}{l}23.9 \\
(17.7- \\
32.1)\end{array}$ & $\begin{array}{l}11.1 \\
(4.9- \\
34.0)\end{array}$ & $\begin{array}{l}30.4 \\
(13.2- \\
52.7)\end{array}$ & NA & NA & $\begin{array}{l}15.2 \\
(8.1- \\
22.5)\end{array}$ & $\begin{array}{l}13.3 \\
(7.5- \\
20.5)\end{array}$ & $\begin{array}{l}15.2 \\
(8.1- \\
22.5)\end{array}$ & $\begin{array}{l}15.0 \\
(10.4- \\
26.0)\end{array}$ \\
\hline Macrolide & $\begin{array}{l}2.9 \\
(1.8- \\
3.4)\end{array}$ & 5.4 & $\begin{array}{l}2.8 \\
(1.9- \\
3.6)\end{array}$ & 12.7 & $\begin{array}{l}6.6 \\
(2.6- \\
14.5)\end{array}$ & $\begin{array}{l}7.7 \\
(3.2- \\
12.7)\end{array}$ & NA & NA & NA & NA & $\begin{array}{l}15.2 \\
(8.1- \\
22.5)\end{array}$ & $\begin{array}{l}13.3 \\
(7.5- \\
20.5)\end{array}$ & NA & NA & NA & NA \\
\hline
\end{tabular}

a Cefixime; ESCephalosporin Extended Spectrum Cephalosporin, FD Fold Difference in antimicrobial consumption between highest and lowest consumption country-year, NA Not Available/Not Applicable 
Table 2 Mixed-Effects Linear Regression Analyses of the Relationship Between Antimicrobial Resistance (AMR) in N. gonorrhoeae with other pathobionts in 30 European countries

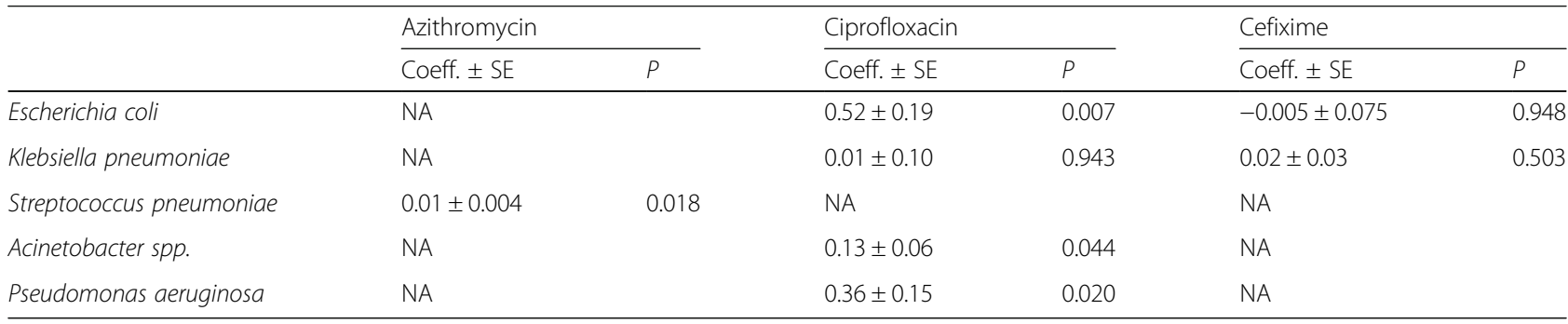

NA Not Available/Not Applicable, SE Standard Error

population [7]. This feature would result in it being more exposed to antimicrobial selection pressure in high consumption populations than lower prevalence bacteria $[7,28]$. Studies from Europe and elsewhere have found community level consumption of antibiotics such as fluoroquinolones to be strongly associated with AMR in E. coli [29]. A weaker or no association has been found with bacteria whose prevalence is lower and where the nosocomial acquisition of AMR is more important such as K. pneumoniae [28].

Since 2012, the prevalence of macrolide resistance in $N$. gonorrhoeae has been slowly increasing in Europe [23]. By 2018, the prevalence of azithromycin resistance exceeded $10 \%$ in 10 countries (Figure S2). European treatment guidelines have recommended azithromycin together with ceftriaxone as dual therapy for gonorrhoea since 2012 [30], which represents one possible explanation for this increase [31]. This should not, however, explain the increase in AMR in certain European countries but not others. No individual or ecological-level study that we are aware of has found an association between dual therapy and azithromycin reduced susceptibility. European guidelines for non-gonococcal urethritis have strongly advocated doxycycline over azithromycin to prevent bystander selection for macrolide resistance selection in other STIs [32]. This should have lessened the STI bystander selection pressure. Our finding that gonococcal macrolide resistance is weakly associated with resistance in $S$. pneumoniae suggests that community-level macrolide consumption may be playing a role. This may sound odd considering we found no statistically significant association between macrolide consumption and resistance in $N$. gonorrhoeae. Macrolide exposure is, however, a well-established determinant of AMR in both species [14,33] and was associated with resistance in $S$. pneumoniae. The considerably lower prevalence of gono- compared to pneumococcus as well as biological differences between the organisms may explain the weaker association between consumption and resistance in $N$. gonorrhoea. There are significant parallels between the pathways to macrolide resistance in these two bacteria. In both, resistance is mediated by $23 \mathrm{~S}$ rRNA target modification and enhanced efflux, conferring high- and low-level resistance, respectively [19, 34, 35]. Furthermore, in both, horizontal gene transfer (via transformation or transposons) from commensal oro- and naso-pharyngeal Streptococci/Neisseria has been shown to play an important role in macrolide resistance via uptake of DNA that results in enhanced efflux of macrolides [19, 35, 36]. A single dose of a macrolide can result in long term (over 6-month) elevations in the proportion of commensal Streptococci [37] and possibly commensal Neisseria [18, 38] with macrolide resistance. This means that a gono- or pneumococcal pharyngeal infection many months after a dose of macrolides may still be able to take up the resistance-conferring DNA from commensals. This delayed effect between

Table 3 Mixed-Effects Linear Regression Analyses of the Relationship Between Antimicrobial Resistance (AMR) and homologous class Antimicrobial Consumption Among Select Pathobionts in 30 European countries

\begin{tabular}{|c|c|c|c|c|c|c|}
\hline & \multicolumn{2}{|c|}{ Azithromycin } & \multicolumn{2}{|c|}{ Ciprofloxacin } & \multicolumn{2}{|l|}{ ESC/Cefixime } \\
\hline & Coeff. \pm SE & $P$ & Coeff. \pm SE & $P$ & Coeff. \pm SE & $P$ \\
\hline Escherichia coli & NA & & $6.13 \pm 0.60$ & $<0.001$ & $0.52 \pm 0.155$ & 0.155 \\
\hline Klebsiella pneumoniae & NA & & $5.44 \pm 1.20$ & $<0.001$ & $-0.08 \pm 077$ & 0.910 \\
\hline Streptococcus pneumoniae & $2.39 \pm 0.61$ & $<0.001$ & NA & & NA & \\
\hline Acinetobacter spp. & NA & & $4.75 \pm 1.34$ & $<0.001$ & NA & \\
\hline Pseudomonas aeruginosa & NA & & $0.34 \pm 0.82$ & 0.676 & NA & \\
\hline Neisseria gonorrhoeae & $0.52 \pm 0.40$ & 0.181 & $3.86 \pm 1.94$ & 0.047 & $0.49 \pm 0.29$ & 0.095 \\
\hline
\end{tabular}

NA Not Available/Not Applicable, ESC Extended Spectrum Cephalosporins, SE Standard Error 
antimicrobial consumption and resistance may make it more difficult to detect in traditional epidemiological studies.

Further investigations to confirm these associations and elucidate the underlying pathways are required. We evaluated a very limited number of bacteria and found $E$. coli and S. pneumoniae to have the strongest associations with gonococcal fluoroquinolone and macrolide resistance, respectively. It is possible that the associations may be stronger in other species. Crucially there is a need to monitor AMR in commensal Neisseria species in populations at high risk for gonococcal AMR $[39,40]$.

For both macrolides and fluoroquinolones, our results represent additional evidence for the community antibiotic theory. More specifically, they suggest that gonococcal antimicrobial resistance can be productively viewed as being part of a syndemic of resistance. The results, therefore, build on those from global analyses which found that a likely key reason why gonococcal AMR frequently emerged in core groups in Asia and elsewhere, was related to high consumption of antimicrobials in these populations [11, 40, 41]. ESCephalosporin resistance, for example, first emerged in Japan [19]. At least in part, this was likely due to the extraordinary high ESCephalosporin consumption in Japan at the time over double the consumption of the country with the next highest consumption [11]. ESCephalosporin AMR emerged rapidly in other organisms in the Asia Pacific region around the same time but, as was the case with $N$. gonorrhoeae, it did not spread uniformly throughout the region [42-44]. In the rural parts of Northern Territory, Australia, for example, there is almost no gonococcal resistance to ESCephalosporins or azithromycin, a finding that is likely attributable to low antimicrobial consumption [43, 45]. Likewise, a phylogenetic analysis of 419 isolates from around the world found that modern gonococci were split into two lineages [41]. Lineage A was found to have arisen in Asia and had a high prevalence of AMR associated mutations (modal number of AMR mutations 7). This was thought to be due to high exposure to antimicrobials. The African lineage B, however, had far fewer AMR associated mutations (modal number of AMR mutations 0) - presumably due to lower antimicrobial exposure. These findings of populations with low levels of gonococcal AMR are important because they reveal that gonococcal AMR is not as inevitable as is commonly supposed but may be prevented or delayed [11, 46].

There are a number of important limitations to this analysis. The EARS-Net data are not based on uniform central testing of isolates. The breakpoints for resistance have also changed during the period under investigation. For example, EUCAST lowered its fluoroquinolone breakpoints for resistance in K. pneumoniae in 2016, which could influence longitudinal analyses such as the current one [28]. We did not adjust our analyses for either differences in MIC testing strategies or changes in breakpoints over time. In both cases, these factors would operate as misclassification biases which typically result in a bias towards the null hypothesis [47]. This would be expected to reduce the statistical strength of any association found. Our measure of antimicrobial consumption was based on ESAC data whose consumption estimates are very similar to those produced by different methodologies such as that used by IQVIA-MIDAS $[48,49]$. We were unable to assess exposure using alternative measures such as days of therapy. The measure of consumption used does not, however, include consumption in hospitals which is an important determinant of AMR for some of the bacteria we evaluated. We were also unable to control for confounders, such as various environmental and socioeconomic variables that are associated with the spread of AMR [50]. It is also possible that STI services in high antimicrobial consumption countries may be more likely to prescribe antibiotics to clients than those in low consumption countries. Whilst we did not control for this in our models, it could be argued that it would be inappropriate to control for this since this is an effect mediator rather than a confounder. Finally, it is possible that a selection bias pertained whereby certain countries were more likely to send more resistant isolates for $N$. gonorrhoeae and the other bacteria. The fact that the $N$. gonorrhoeae AMR data is obtained from the Euro-GRASP survey, which has a separate surveillance system and does not depend on isolates from blood cultures makes this bias less likely. Validation studies have also concluded that, with the exception of beta-lactam resistance in S. pneumoniae and plasmid-mediated colistin resistance in the Enterobacteriaceae, the EARS-net AMR prevalence estimates are relatively accurate [51].

Evidence that gonococcal AMR is part of a syndemic of resistance is an important finding as it suggests that minimizing the probability of further AMR emerging in $N$. gonorrhoeae would benefit from antibiotic stewardship campaigns to reduce total consumption of antibiotics. The probability of bystander selection affecting $N$. gonorrhoeae is considerably higher in core-groups such as HIV preexposure prophylaxis populations where the prevalence of $N$. gonorrhoeae is around $10 \%[52,53]$. Gonococcal AMR has also frequently emerged in these types of core groups with high gonococcal prevalence and high antimicrobial consumption [40,53]. As a result, it may be prudent to focus stewardship campaigns on both general populations with high antimicrobial consumption as well as core-groups in all populations [54].

\section{Supplementary information}

Supplementary information accompanies this paper at https://doi.org/10. 1186/s13756-020-00764-z.

Additional file 1 Figure S1. Fluoroquinolone (FQ) consumption and prevalence of antimicrobial resistance to fluoroquinolones in Neisseria 
gonorrhoeae ( $\mathrm{Ng}$ ) and Escherichia coli (Ec) in 30 European countries. Figure S2. Macrolide consumption and prevalence of antimicrobial resistance to azithromycin in Neisseria gonorrhoeae $(\mathrm{Ng})$ and macrolides in Streptococcus pneumoniae (Sp) in 30 European countries.

\section{Acknowledgements}

We would like to thank the ECDC for the data provided on their Surveillance Atlas of Infectious Diseases.

\section{Authors' contributions}

CK conceptualized the study. CK was responsible for the acquisition, analysis and interpretation of data. CK, CVD and SMB read and approved the final draft.

\section{Funding}

No specific funding was received for this work

\section{Availability of data and materials}

The data we used is publicly available from: https://atlas.ecdc.europa.eu/

\section{Consent for publication}

Not applicable.

\section{Competing interests}

None to declare. All the authors declare that they have no conflicts of interest.

Received: 4 March 2020 Accepted: 23 June 2020

Published online: 30 June 2020

\section{References}

1. Wi T, Lahra MM, Ndowa F, Bala M, Dillon JR, Ramon-Pardo P, et al, Antimicrobial resistance in Neisseria gonorrhoeae: Global surveillance and a call for international collaborative action. PLOS Med. 2017:14(7):e1002344. https://doi.org/10.1371/journal.pmed.1002344 Epub 2017/07/08. PubMed PMID: 28686231; PubMed Central PMCID: PMCPMC5501266.

2. Unemo M, Nicholas RA. Emergence of multidrug-resistant, extensively drugresistant and untreatable gonorrhea. Future Microbiol. 2012;7(12):1401-22. https://doi.org/10.2217/fmb.12.117 Epub 2012/12/13. PubMed PMID: 23231489; PubMed Central PMCID: PMCPMC3629839.

3. European Centre for Disease Prevention and Control. Extensively drugresistant (XDR) Neisseria gonorrhoeae in the United Kingdom and Australia. Stockholm: ECDC; 2018.

4. Lankford C. The in vitro tolerance of the gonococcus for penicillin. Am J Syphilis. 1945:29(1):56-63.

5. Del Love B, Finland M. Susceptibility of Neisseria gonorrhoeae to eleven antibiotics and sulfadiazine. Comparison of susceptibility of recently isolated strains with results obtained in previous years in the same laboratory. Arch Intern Med. 1955;95(1):66-73.

6. Willcox RR. A survey of problems in the antibiotic treatment of gonorrhoea. With special reference to South-East Asia. Br J Vener Dis. 1970;46(3):217-42. https://doi.org/10.1136/sti.46.3.217 Epub 1970/06/01. . PubMed PMID: 4246923; PubMed Central PMCID: PMCPMC1048070.

7. Tedijanto C, Olesen SW, Grad YH, Lipsitch M. Estimating the proportion of bystander selection for antibiotic resistance among potentially pathogenic bacterial flora. Proc Natl Acad Sci U S A. 2018;115(51):E11988-E95. https:// doi.org/10.1073/pnas.1810840115 Epub 2018/12/19. PubMed PMID: 30559213: PubMed Central PMCID: PMCPMC6304942.

8. Fernandez-Huerta M, Barbera MJ, Serra-Pladevall J, Esperalba J, MartinezGomez X, Centeno C, et al. Mycoplasma genitalium and antimicrobial resistance in Europe: a comprehensive review. Int J STD AIDS. 2020; 956462419890737. https://doi.org/10.1177/0956462419890737 Epub 2020/ 02/01. PubMed PMID: 32000587.

9. Unemo M, Bradshaw CS, Hocking JS, de Vries HJC, Francis SC, Mabey D, et al. Sexually transmitted infections: challenges ahead. Lancet Infect Dis. 2017;17(8):e235-e79. https://doi.org/10.1016/S1473-3099(17)30310-9 Epub 2017/07/14. PubMed PMID: 28701272

10. Kenyon C. Prevalence of macrolide resistance in Treponema pallidum is associated with macrolide consumption. J Med Microbiol. 2018;68(2):119-23. https://doi.org/10.1099/jmm.0.000885. Epub 2018 Dec 6.
11. Kenyon C, Buyze J, Wi T. Antimicrobial consumption and susceptibility of Neisseria gonorrhoeae: a global ecological analysis. Front Med. 2018:5:329.

12. Kirkcaldy RD, Bartoces MG, Soge OO, Riedel S, Kubin G, Del Rio C, et al. Antimicrobial Drug Prescription and Neisseria gonorrhoeae Susceptibility, United States, 2005-2013. Emerg Infect Dis. 2017;23(10):1657-63. https://doi. org/10.3201/eid2310.170488 PubMed PMID: 28930001; PubMed Central PMCID: PMCPMC5621530. Epub 2017/09/21.

13. Kenyon C, Buyze J, Spiteri G, Cole M, Unemo M. Population-level antimicrobial consumption is associated with decreased antimicrobial susceptibility in Neisseria gonorrhoeae in 24 European countries: an ecological analysis. J Infect Dis. 2019;[Epub ahead of print]. Epub Apr 8. https://doi.org/10.1093/infdis/jiz153.

14. Olesen SW, Torrone EA, Papp JR, Kirkcaldy RD, Lipsitch M, Grad YH. Azithromycin Susceptibility Among Neisseria gonorrhoeae Isolates and Seasonal Macrolide Use. J Infect Dis. 2019;219(4):619-23. https://doi.org/10. 1093/infdis/jiy551 PubMed PMID: 30239814; PubMed Central PMCID: PMCPMC6350947. Epub 2018/09/22.

15. Turnidge J, Christiansen K. Antibiotic use,and resistance - proving the obvious. Lancet. 2005:365(9459):548-9 PubMed PMID: WOS: 000226984300004

16. Abraha M, Egli-Gany D, Low N. Epidemiological, behavioural, and clinical factors associated with antimicrobial-resistant gonorrhoea: a review. F1000Research. 2018;7:400. https://doi.org/10.12688/f1000research.13600.1.

17. Jakobsson HE, Jernberg C, Andersson AF, Sjolund-Karlsson M, Jansson JK, Engstrand L. Short-term antibiotic treatment has differing long-term impacts on the human throat and gut microbiome. PLoS One. 2010;5(3): e9836. https://doi.org/10.1371/journal.pone.0009836 PubMed PMID: 20352091: PubMed Central PMCID: PMC2844414

18. Furuya $R$, Onoye $Y$, Kanayama A, Saika T, lyoda T, Tatewaki M, et al. Antimicrobial resistance in clinical isolates of Neisseria subflava from the oral cavities of a Japanese population. J Infect Chemother. 2007;13(5):302-4. https://doi.org/10.1007/s10156-007-0541-8 Epub 2007/11/06. PubMed PMID: 17982718

19. Unemo M, Shafer WM. Antimicrobial resistance in Neisseria gonorrhoeae in the 21st century: past, evolution, and future. Clin Microbiol Rev. 2014;27(3): 587-613. https://doi.org/10.1128/CMR.00010-14 PubMed PMID: 24982323; PubMed Central PMCID: PMCPMC4135894.

20. Van Dijck C, Laumen JGE, Manoharan-Basil SS, Kenyon C. Commensal Neisseria Are Shared between Sexual Partners: Implications for Gonococcal and Meningococcal Antimicrobial Resistance. Pathogens. 2020;9(3). Edoi: https://doi.org/10.3390/pathogens9030228. PubMed PMID: 32204480; PubMed Central PMCID: PMCPMC7157722. pub 2020/03/25

21. European Centre for Disease Prevention and Control. TESSy, The European Surveillance System - Antimicrobial resistance (AMR) reporting protocol 2019 - European Antimicrobial Resistance Surveillance Network (EARS-Net) surveillance data for 2018. Stockholm: ECDC; 2019

22. Spiteri G, Cole M, Unemo M, Hoffmann S, Ison C, van de Laar M. The European Gonococcal Antimicrobial Surveillance Programme (Euro-GASP)-a sentinel approach in the European Union (EU)/European Economic Area (EEA). Sex Transm Infect. 2013;89(Suppl 4):iv16-8. https://doi.org/10.1136/ sextrans-2013-051117 PubMed PMID: 24243874. Epub 2013/11/28.

23. Cole MJ, Spiteri G, Jacobsson S, Woodford N, Tripodo F, Amato-Gauci AJ, et al. Overall Low Extended-Spectrum Cephalosporin Resistance but high Azithromycin Resistance in Neisseria gonorrhoeae in 24 European Countries, 2015. BMC Infect Dis. 2017;17(1):617. https://doi.org/10.1186/s12879-0172707-z PubMed PMID: 28893203; PubMed Central PMCID: PMCPMC5594611. Epub 2017/09/13.

24. European Centre for Disease Prevention and Control. Gonococcal antimicrobial susceptibility surveillance in Europe, 2015. Stockholm: ECDC; 2017.

25. European Centre for Disease Prevention and Control. Annual epidemiological report for 2015. Antimicrobial Consumption. Stockholm: ECDC; 2018

26. Vander Stichele RH, Elseviers MM, Ferech M, Blot S, Goossens H, Group EP. European surveillance of antimicrobial consumption (ESAC): data collection performance and methodological approach. Br J Clin Pharmacol. 2004;58(4): 419-28. https://doi.org/10.1111/j.1365-2125.2004.02164.x PubMed PMID: 15373935; PubMed Central PMCID: PMCPMC1884596. Epub 2004/09/18

27. Organization $\mathrm{WH}$. The anatomical therapeutic chemical classification system with defined daily doses (ATC/DDD). Oslo: WHO; 2006.

28. European Centre for Disease Prevention Control. Surveillance of antimicrobial resistance in Europe 2018. Stockholm: ECDC; 2019. 
29. ECDC/EFSA/EMA. ECDC/EFSA/EMA second joint report on the integrated analysis of the consumption of antimicrobial agents and occurrence of antimicrobial resistance in bacteria from humans and food-producing animals: Joint Interagency Antimicrobial Consumption and Resistance Analysis (JIACRA) Report. Efsa J. 2017;15(7). https://doi.org/10.2903/j.efsa. 2017.4872 UNSP 4872. PubMed PMID: WOS:000406685200007.

30. Bignell C, Unemo M, European STIGEB. 2012 European guideline on the diagnosis and treatment of gonorrhoea in adults. Int J STD AIDS. 2013;24(2): 85-92. https://doi.org/10.1177/0956462412472837 PubMed PMID: 24400344.

31. Unemo M, Workowski K. Dual antimicrobial therapy for gonorrhoea: what is the role of azithromycin? Lancet Infect Dis. 2018;18(5):486-8.

32. Horner PJ, Blee K, Falk L, van der Meijden W, Moi H. 2016 European guideline on the management of non-gonococcal urethritis. Int J STD AIDS. 2016:928-37.

33. Bergman M, Huikko S, Huovinen P, Paakkari $P$, Seppala H, Finnish Study Group for Antimicrobial R. Macrolide and azithromycin use are linked to increased macrolide resistance in Streptococcus pneumoniae. Antimicrob Agents Chemother. 2006;50(11):3646-50. https://doi.org/10.1128/AAC.0023406 Epub 2006/08/31. PubMed PMID: 16940064; PubMed Central PMCID: PMCPMC1635217.

34. Weisblum B. Erythromycin resistance by ribosome modification. Antimicrob Agents Chemother. 1995;39(3):577-85. https://doi.org/10.1128/aac.39.3.577 PubMed PMID: 7793855; PubMed Central PMCID: PMCPMC162587. Epub 1995/03/01.

35. McGee L, Klugman P. Resistance in Streptococcus pneumoniae. In: Mayers DL, Sobel JD, Ouellette M, Kaye KS, Marchaim D, editors. Antimicrobial drug resistance: Clinical and epidemiological aspects. 2. London: Springer; 2017.

36. Wadsworth CB, Arnold BJ, Sater MRA, Grad YH. Azithromycin Resistance through Interspecific Acquisition of an Epistasis-Dependent Efflux Pump Component and Transcriptional Regulator in Neisseria gonorrhoeae. Mbio. 2018;9(4). https://doi.org/10.1128/mBio.01419-18 ARTN e01419-18. PubMed PMID: WOS:000443884300078.

37. Malhotra-Kumar S, Lammens C, Coenen S, Van Herck K, Goossens H. Effect of azithromycin and clarithromycin therapy on pharyngeal carriage of macrolide-resistant streptococci in healthy volunteers: a randomised, double-blind, placebo-controlled study. Lancet. 2007;369(9560):482-90.

38. Laumen JGE, Van Dijck C, Abdellati S, Manoharan-Basil SS, De Baetselier I, Martiny D, et al. Markedly reduced azithromycin and ceftriaxone susceptibility in commensal Neisseria species in clinical samples from Belgian men who have sex with men. Clin Infect Dis. 2020. https://doi.org/ 10.1093/cid/ciaa565 PubMed PMID: 32402070. . Epub 2020/05/14.

39. Dong HV, Pham LQ, Nguyen HT, MXB N, Nguyen TV, May F, et al. Decreased Cephalosporin Susceptibility of Oropharyngeal Neisseria Species in Antibiotic-Using Men-who-have-sex-with-men of Hanoi, Vietnam. Clin Infect Dis. 2019. https://doi.org/10.1093/cid/ciz365 PubMed PMID: 31049592. Epub 2019/05/03

40. Lewis DA. The role of core groups in the emergence and dissemination of antimicrobial-resistant N gonorrhoeae. Sex Transm Infect. 2013;89(Suppl 4): iv47-51. https://doi.org/10.1136/sextrans-2013-051020 PubMed PMID: 24243880

41. Sanchez-Buso L, Golparian D, Corander J, Grad YH, Ohnishi M, Flemming R, et al. The impact of antimicrobials on gonococcal evolution. Nat Microbiol. 2019;4(11):1941-50. https://doi.org/10.1038/s41564-019-0501-y PubMed PMID: 31358980; PubMed Central PMCID: PMCPMC6817357. Epub 2019/07/ 31.

42. Lai CC, Lee K, Xiao Y, Ahmad N, Veeraraghavan B, Thamlikitkul V, et al. High burden of antimicrobial drug resistance in Asia. J Glob Antimicrob Resist. 2014;2(3):141-7. https://doi.org/10.1016/j.jgar.2014.02.007 Epub 2014/09/01. PubMed PMID: 27873720.

43. CRR G, Enriquez RP, Gatus BJ, Whiley DM, Lo YR, Ishikawa N, et al. Systematic review and survey of Neisseria gonorrhoeae ceftriaxone and azithromycin susceptibility data in the Asia Pacific, 2011 to 2016. PLoS One. 2019;14(4):e0213312. https://doi.org/10.1371/journal.pone.0213312 Epub 2019/04/04. PubMed PMID: 30943199; PubMed Central PMCID: PMCPMC6447224 following competing interests: David M. Whiley reports research funding from SpeeDx Pty Ltd. This research involves the development of molecular-based tests for Neisseria gonorrhoeae antimicrobial resistance. This does not alter our adherence to PLOS ONE policies on sharing data and materials.

44. Yam ELY, Hsu LY, Yap EP, Yeo TW, Lee V, Schlundt J, et al. Antimicrobial Resistance in the Asia Pacific region: a meeting report. Antimicrob Resist
Infect Control. 2019;8:202. https://doi.org/10.1186/s13756-019-0654-8 Epub 2020/01/01. PubMed PMID: 31890158; PubMed Central PMCID: PMCPMC6921568

45. Whiley DM, Trembizki E, Buckley C, Freeman K, Baird RW, Beaman M, et al. Molecular Antimicrobial Resistance Surveillance for Neisseria gonorrhoeae, Northern Territory, Australia. Emerg Infect Dis. 2017;23(9):1478-85. https:// doi.org/10.3201/eid2309.170427 Epub 2017/08/19. PubMed PMID: 28820128; PubMed Central PMCID: PMCPMC5572890.

46. Blomquist PB, Miari VF, Biddulph JP, Charalambous BM. Is gonorrhea becoming untreatable? Future Microbiol. 2014;9(2):189-201.

47. Chyou P-H. Patterns of bias due to differential misclassification by casecontrol status in a case-control study. Eur J Epidemiol. 2007;22(1):7.

48. Klein EY, Van Boeckel TP, Martinez EM, Pant S, Gandra S, Levin SA, et al. Global increase and geographic convergence in antibiotic consumption between 2000 and 2015. Proc Natl Acad Sci U S A. 2018;115(15):E3463-E70. https://doi.org/10.1073/pnas.1717295115 Epub 2018/03/28. PubMed PMID: 29581252; PubMed Central PMCID: PMCPMC5899442.

49. European Centre for Disease Prevention and Control. Antimicrobial resistance surveillance in Europe 2015. Annual report of the European Antimicrobial Resistance Surveillance Network (EARS-Net). Stockholm: ECDC; 2015.

50. Collignon P, Beggs JJ, Walsh TR, Gandra S, Laxminarayan R. Anthropological and socioeconomic factors contributing to global antimicrobial resistance: a univariate and multivariable analysis. Lancet Planet Health. 2018;2(9):e398405. https://doi.org/10.1016/S2542-5196(18)30186-4 Epub 2018/09/05. PubMed PMID: 30177008.

51. European Centre for Disease Prevention and Control. External quality assessment (EQA) of performance of laboratories participating in the European Antimicrobial Resistance Surveillance Network (EARSNet), 2018. Stockholm: ECDC; 2019.

52. Tsoumanis A, Hens N, Kenyon CR. Is screening for chlamydia and gonorrhea in men who have sex with men associated with reduction of the prevalence of these infections? A systematic review of observational studies. Sex Transm Dis. 2018;45(9):615-22.

53. Kenyon CR, Schwartz IS. Effects of Sexual Network Connectivity and Antimicrobial Drug Use on Antimicrobial Resistance in Neisseria gonorrhoeae. Emerg Infect Dis. 2018;24(7):1195-203. https://doi.org/10.3201/ eid2407.172104 Epub 2018/06/19. PubMed PMID: 29912682; PubMed Central PMCID: PMCPMC6038757.

54. Kenyon C. We need to consider collateral damage to resistomes when we decide how frequently to screen for chlamydia/gonorrhoea in PrEP cohorts. AIDS. 2019;33:155-7.

\section{Publisher's Note}

Springer Nature remains neutral with regard to jurisdictional claims in published maps and institutional affiliations.

Ready to submit your research? Choose BMC and benefit from:

- fast, convenient online submission

- thorough peer review by experienced researchers in your field

- rapid publication on acceptance

- support for research data, including large and complex data types

- gold Open Access which fosters wider collaboration and increased citations

- maximum visibility for your research: over $100 \mathrm{M}$ website views per year

At BMC, research is always in progress.

Learn more biomedcentral.com/submissions 